\title{
Urinary C-megalin for screening of renal scarring in children after febrile urinary tract infection
}

\author{
Sohsaku Yamanouchi ${ }^{1}$, Takahisa Kimata ${ }^{1}$, Jiro Kino ${ }^{1}$, Tetsuya Kitao ${ }^{1}$, Chikushi Suruda ${ }^{1}$, Shoji Tsuji ${ }^{1}$, Hiroyuki Kurosawa ${ }^{2}$, \\ Yoshiaki Hirayama ${ }^{2}$, Akihiko Saito ${ }^{3}$ and Kazunari Kaneko ${ }^{1}$
}

BACKGROUND: Febrile urinary tract infection (fUTI) in children may cause renal scarring. This study aimed to investigate the usefulness of urinary biomarkers for diagnosing renal scarring after fUTI.

METHODS: Thirty-seven children (median age: 1.36 years, range: $0.52-12.17$ years, 25 boys) with a history of fUTI, who underwent renal scintigraphy for 4 months or longer after the last episode of fUTI, were analyzed. A spot urine sample was obtained on the day of renal scintigraphy to measure levels of total protein, $N$-acetyl- $\beta$-D-glucosaminidase (NAG), $\beta_{2}$-microglobulin (BMG), neutrophil gelatinase-associated lipocalin (NGAL), liver-type fatty acid binding protein (L-FABP), and C-megalin (full-length megalin). Results were corrected for urinary creatinine $(\mathrm{Cr})$ and compared between the group with renal scarring $(n=23)$ and that without scarring $(n=14)$. Urinary levels of C-megalin were also measured in healthy control subjects.

RESULTS: No significant differences in total protein, NGAL, $L-F A B P, N A G$, and BMG levels were found between the groups. However, C-megalin levels were significantly higher in the renal scarring group than in the non-renal scarring group and healthy controls $(P<0.001)$. A cutoff value of $6.5 \mathrm{pmol} /$ $\mathrm{nmol}$ of urinary C-megalin/ $\mathrm{Cr}$ yielded $73.9 \%$ of specificity and 92.9\% of sensitivity.

CONCLUSION: Urinary C-megalin is useful for diagnosing renal scarring caused by fUTI.

U rinary tract infection (UTI) is one of the most common illnesses in children. Approximately 3-8\% of girls and 1$2 \%$ of boys have a history of UTI at $6-7$ years of age $(1,2)$. A total of $5 \%$ of children with fever of unknown origin suffer from UTI (3). Renal scarring develops in $10-40 \%$ of children with repeated febrile UTI (fUTI) (4). Risk factors for renal scarring in children after repeated fUTI involve age at presentation, sex, race, peak fever, treatment delay, and the presence of vesicoureteral reflux (VUR) $(3,5,6)$. Children with renal scarring may develop chronic kidney disease in later life, and this eventually leads to end-stage renal disease (ESRD) $(3,7)$. Therefore, patients with repeated fUTI should be diagnosed as having renal scarring as early as possible. These patients should also be carefully observed to determine whether they require surgical treatment or continuous antibiotic prophylaxis to reduce the risk of ESRD (8). Although hypertension, proteinuria, and a low glomerular filtration rate are thought to be predictors of ESRD in patients with renal scarring $(9,10)$, their sensitivities are not sufficient for predictive use in children (11-13). An imaging study using ${ }^{99 \mathrm{~m}}$ technetium-dimercaptosuccinic acid $\left({ }^{99 \mathrm{~m}} \mathrm{Tc}-\mathrm{DMSA}\right)$ renal scintigraphy is essential for diagnosing renal scarring (14); however, it is not available at many local hospitals. Additionally, a considerable amount of radiation exposure is associated with ${ }^{99 \mathrm{~m}} \mathrm{Tc}$-DMSA renal scintigraphy, and this may discourage repeated testing (15). Therefore, noninvasive biomarkers for the diagnosis of renal scarring are strongly desired. However, urinary $N$-acetyl- $\beta$-D-glucosaminidase (NAG) and $\beta_{2}$-microglobulin (BMG) have been used for this purpose but with disappointing results $(11,16)$.

Recently, neutrophil gelatinase-associated lipocalin (NGAL), liver-type fatty acid binding protein (L-FABP), and C-megalin, the full-length form of megalin, have been proposed as new urinary biomarkers for the early diagnosis of kidney injury (17-19). We hypothesize that novel urinary biomarkers have abnormal values in children with renal scarring after repeated fUTI. Therefore, this study evaluated the usefulness of these biomarkers for the diagnosis of renal scaring.

\section{METHODS}

\section{Patients}

For this prospective study, 462 patients were identified as having fUTI at affiliated hospitals of Kansai Medical University between January 2001 and December 2015. The criteria for fUTI are as follows: high fever $\left(>38.5^{\circ} \mathrm{C}\right)$ and single bacterial species of $10^{3} \mathrm{CFU} / \mathrm{ml}$ or greater in urine specimens obtained by catheterization. All patients underwent VCUG to identify the underlying VUR. Patients who were complicated by other febrile diseases were excluded. Among them, 159 fUTI children were recruited to our institution to undergo ${ }^{99 \mathrm{~m}} \mathrm{Tc}$-DMSA renal scintigraphy based on inclusion criteria including risk factors related to the development of renal scar such as high-grade VUR (grades III-V), and/or high fever $\geq 2$ days, and/or repeated fUTI episodes. We finally enrolled 37 patients who provided urine samples on the same day of ${ }^{99 \mathrm{~m}} \mathrm{Tc}$ -

${ }^{1}$ Department of Pediatrics, Kansai Medical University, Hirakata, Japan; ${ }^{2}$ R \& D Center, DENKA SEIKEN Co., Ltd, Gosen, Japan; ${ }^{3}$ Department of Applied Molecular Medicine, Niigata University Graduate School of Medical and Dental Sciences, Niigata, Japan. Correspondence: Kazunari Kaneko (kanekok@hirakata.kmu.ac.jp)

Received 27 June 2017; accepted 6 October 2017; advance online publication 6 December 2017. doi:10.1038/pr.2017.276 


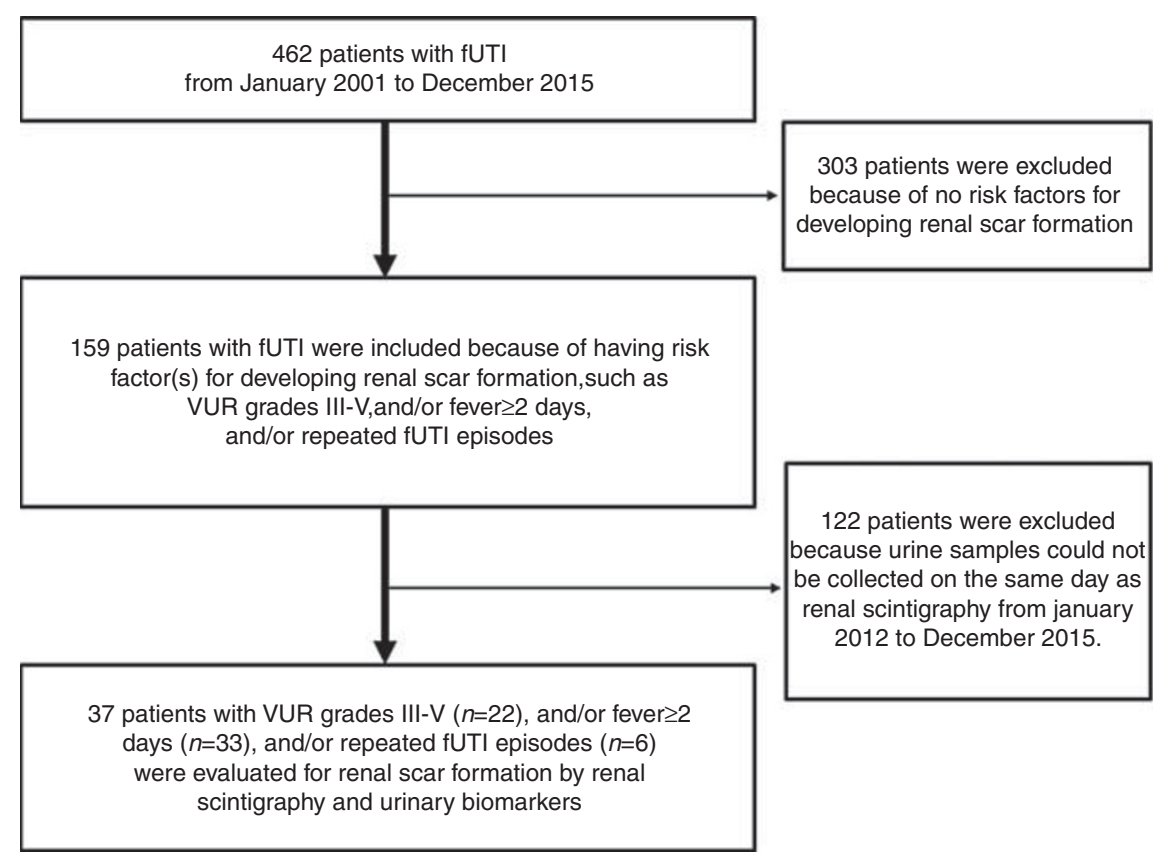

Figure 1. Flow chart showing enrollment of patients. fUTI, febrile urinary tract infection; VUR, vesicoureteral reflux.

DMSA renal scintigraphy between January 2012 and December 2015 when urinary C-megalin measurements became available. The breakdown of the risk factors in the 37 enrolled patients were high-grade VUR $(n=22)$, fever $\geq 2$ days $(n=33)$, and/or repeated fUTI episodes $(n=6)$, while some had more than one factor. Detailed criteria for enrollment in this study are shown in Figure 1.

${ }^{99 m}$ Tc-DMSA renal scintigraphy was performed during the chronic phase (i.e., 4 months or longer after the last episode of fUTI) (20). In all patients, the results of ${ }^{99 \mathrm{~m}} \mathrm{Tc}-\mathrm{DMSA}$ renal scintigraphy were evaluated by a single radiologist who was blinded to the patients' characteristics, such as age, sex, diagnosis, and the presence or absence of VUR.

The severity of renal scarring was evaluated semiquantitatively by dividing the renal cortex into 12 segments. We counted the number of renal parenchyma segments in cortical defects using ${ }^{99 \mathrm{~m}} \mathrm{Tc}$-DMSA renal scintigraphy as follows: one or two segments, mild; three or four segments, moderate; five or more segments, severe; and global atrophy, a diffusely scarred and shrunken kidney (8).

For comparison of urinary C-megalin levels, healthy control subjects, whose guardians were working at the Kansai Medical University Hospital, voluntarily participated in this study and provided urine samples.

This study was performed with the approval of Kansai Medical University ethics committee (No. 1518) in accordance with the principles embodied in the Declaration of Helsinki. Informed consent was obtained from the parents of all individual participants included in the study.

\section{Sampling and Measurement}

All of the patients' urine samples were collected on the same day that ${ }^{99 \mathrm{~m}} \mathrm{Tc}$-DMSA renal scintigraphy was performed. The urine specimens were centrifuged at $427 \mathrm{~g}$ for $5 \mathrm{~min}$. The supernatants were harvested and stored at $-80^{\circ} \mathrm{C}$ until later measurement. The stored urine samples were thawed on the day when NGAL, L-FABP, and $\mathrm{C}$-megalin levels were measured by enzyme-linked immunosorbent assay. Urinary NGAL levels were measured using a kit for human lipocalin-2/NGAL (R\&D Systems, Minneapolis, MN). Urinary L-FABP levels were measured with the Renapro L-FABP test (CMIC Co. Ltd, Tokyo, Japan). C-megalin levels were measured as reported previously (19). Serum levels of creatinine and urinary levels of total protein, NAG, BMG, and creatinine were measured on the same day of sampling by an enzymatic method, the pyrogallol red method, the PNP-GlcNAc substrate method, radioimmunoassay, and an enzymatic method, respectively. For all samples with measured values exceeding the standard curve, the dilution ratio was changed, and the measurements were repeated. Additionally, each patient's medical information related to fUTI at the time of admission was collected from the medical records.

The patients were classified into a renal scarring group (23 patients) and a group without renal scarring (non-renal scarring group, 14 patients). For comparison, healthy control subjects were also included to provide normal levels of urinary C-megalin.

All measured values in urine samples were corrected by urinary levels of creatinine and then compared between the groups.

\section{Statistical Analysis}

The $\chi^{2}$ test for qualitative data, and the Mann-Whitney $U$-test or Kruskal-Wallis Test for numerical data were used to compare values among the groups. The Spearman's rank-sum test was used to determine relationships between the variables. Logistic regression analysis for multivariate analysis was used to identify the associations between risk factors and the presence of renal scarring. All median and quartile values were calculated, and $P<0.05$ was considered statistically significant. We also used receiver operating characteristic curves to compare each urinary biomarker in terms of discriminability on diagnosis of renal scarring.

\section{RESULTS}

\section{Patients' Profiles}

A summary of the patients' profiles based on the presence or absence of renal scarring is shown in Table 1. Findings from ${ }^{99 m}$ Tc-DMSA renal scintigraphy in the convalescent phase of 37 children at a median of 7.1 months (interquartile range (IQR): 5.9-13.3 months) after fUTI showed renal scarring in 23 patients ( 17 boys and 6 girls, median age 2.30 years, range: $0.52-12.17$ years) and no scarring in 14 patients ( 8 boys and 6 girls, median age 1.20 years, range: $0.59-10.39$ years). Healthy 


\section{Articles | Yamanouchi et al.}

age-matched controls were 20 children consisting of 9 boys and 11 girls (median age 3.24 years, range: $0.40-5.52$ years). No significant differences in sex, age, and the prevalence of VUR were found between the two patients groups. Overall, 16 of $23(70 \%)$ patients in the renal scarring group and 6 of 14 $(43 \%)$ in the non-renal scarring group had high-grade (grades III-V) VUR. There was no significant difference in the prevalence of high-grade VUR between the groups. Additionally, there were no significant differences in the frequency of fUTI, duration of fever, and highest level of C-reactive protein in the acute phase between the groups (Table 1).

\section{Urinary Biomarkers}

Because urinary total protein was undetectable $(<4 \mathrm{mg} / \mathrm{dl})$ in most patients of both groups (19 of 23 in the renal scarring group and 11 of 14 in the non-renal scarring group), further analysis was not performed. The urinary levels of NAG, NGAL, L-FABP, and BMG were not significantly different between the groups. Similarly, serum levels of creatinine and cystatin $\mathrm{C}$ were also not different between the groups. In contrast, the median urinary C-megalin level was significantly

Table 1. Patients' profiles with and without renal scarring

\begin{tabular}{lccc}
\hline Renal scarring & Present $(\mathrm{n}=23)$ & Absent $(\mathrm{n}=14)$ & P value \\
\hline Age (years) & $2.30(0.52-12.17)$ & $1.20(0.59-10.39)$ & 0.30 \\
$\begin{array}{l}\text { Sex (male/female) } \\
\text { Presence of VUR (\%) }\end{array}$ & $17: 6$ & $8: 6$ & 0.49 \\
& & $11(79)$ & 0.88 \\
VUR grade (\%) & & & \\
$\quad$ Low (I-II) & $3(13)$ & $5(36)$ & 0.18 \\
$\quad$ High (III-V) & $16(70)$ & $6(43)$ & \\
Frequency of fUTI & $1(1-2)$ & $1(1-2)$ & 0.76 \\
$\begin{array}{l}\text { Days of fever } \\
\text { Highest level of CRP } \\
\text { (mg/l) }\end{array}$ & $3(1-8)$ & $3(1-6)$ & 0.92 \\
\hline
\end{tabular}

Median values are expressed with minimum-maximum value in parentheses. CRP, C-reactive protein; fUTI, febrile urinary tract infection; ${ }^{99 \mathrm{~m}} \mathrm{Tc}-\mathrm{DMSA},{ }^{99 \mathrm{~m}}$ technetiumdimercaptosuccinic acid; VUR, vesicoureteral reflux. higher in the renal scarring group $(8.84 \mathrm{pmol} / \mathrm{nmol}$, IQR: 5.64-21.30) than in the non-renal scarring group (1.34 pmol/ nmol, IQR: $0.00-2.69, P<0.001$; Table 2 and Figure 2). Furthermore, urinary C-megalin level was significantly higher in the renal scarring group compared with healthy agematched children $(P<0.05)$, but no significant difference was observed between the non-renal scarring group and the healthy age-matched children (Figure 2).

In the area under the receiver operating characteristic curve, which was calculated for each urinary biomarker, C-megalin yielded the highest value: C-megalin (0.85) > NAGL (0.64) $>$ L-FABP (0.61) > NAG (0.43)> BMG (0.42). These results indicated that $\mathrm{C}$-megalin had the highest discriminability for diagnosis of renal scarring (Figure 3 ). To determine a cutoff value for urinary $\mathrm{C}$-megalin to identify renal scars, the specificity, sensitivity, positive predictive value, and negative predictive value dependent on various urinary C-megalin

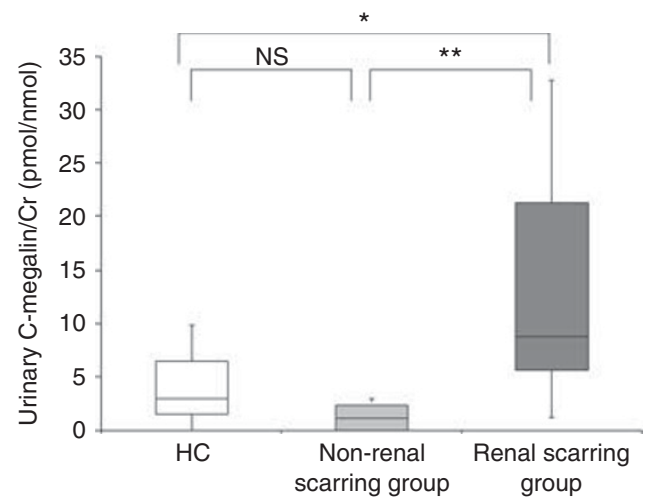

Figure 2. Urinary C-megalin levels in patients with/without renal scarring and healthy children. The median urinary C-megalin level was increased in the renal scarring group $(n=23)$ compared with the nonrenal scarring group $(n=14)$ and the healthy age-matched group $(n=20)$. There was no significant difference between the non-renal scarring group and the healthy age-matched group. Box central horizontal line, median; bottom and top edges, 25th and 75th percentiles, respectively. Central vertical lines extend from the box to the 90 th or 10 th percentile. ${ }^{*} P<0.05,{ }^{*} P<0.01$. NS, not significant. HC, healthy control children.

Table 2. Blood and urinary biomarkers for identifying renal scarring

\begin{tabular}{lccc}
\hline Renal scarring & Present & Absent & P value \\
\hline Urine & & & \\
C-megalin/Cr $(\mathrm{pmol} / \mathrm{nmol})$ & $8.84(5.64-21.30)$ & $1.34(0.00-2.69)$ & 0.0004 \\
$\mathrm{NAG} / \mathrm{Cr}(\mathrm{IU} / \mathrm{nmol})$ & $6.16(2.51-9.54)$ & $7.29(5.49-11.85)$ & 0.46 \\
$\mathrm{NGAL} / \mathrm{Cr}(\mathrm{ng} / \mu \mathrm{mol})$ & $19.25(3.84-40.36)$ & $14.15(10.30-21.75)$ & 0.28 \\
$\mathrm{~L}-\mathrm{FABP} / \mathrm{Cr}(\mathrm{ng} / \mu \mathrm{mol})$ & $3.95(0.00-5.24)$ & $0.36(0.00-4.03)$ & 0.48 \\
$\mathrm{BMG} / \mathrm{Cr}(\mu \mathrm{gg} / \mu \mathrm{mol})$ & $0.37(0.15-0.48)$ & & 0.46
\end{tabular}

Blood

$\mathrm{Cr}(\mu \mathrm{mol} / \mathrm{l})$

$20.33(17.68-22.98)$

$21.22(18.56-30.06)$

0.23

Cys C (mg/l)

$0.76(0.74-0.93)$

$0.80(0.71-0.90)$

0.80

Median values are expressed with interquartile range in parentheses. BMG, $\beta_{2}$-microglobulin; $C r$, creatinine; Cys-C, cystatin-C; L-FABP, liver-type fatty acid binding protein; NAG,

$N$-acetyl- $\beta$-D-glucosaminidase; NGAL, neutrophil gelatinase-associated lipocalin. 


\section{Urinary C-megalin and renal scarring $\mid$ Articles}

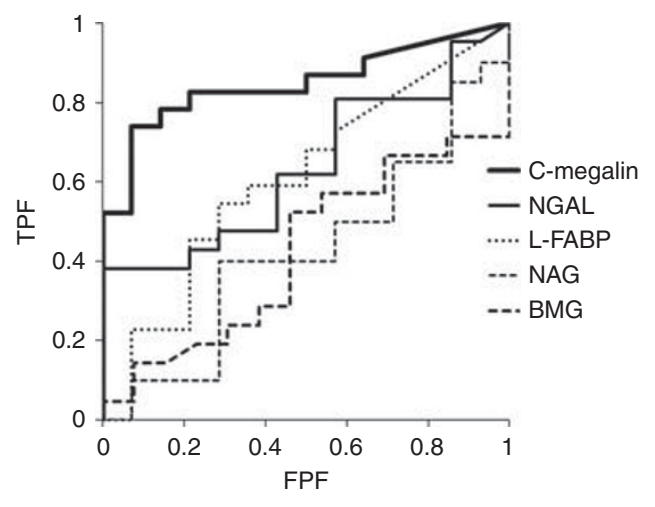

Figure 3. Ability to identify renal scarring with each urinary biomarker. $B M G, \beta_{2}$-microglobulin; FPF, false-positive fraction; L-FABP, liver-type fatty acid binding protein; NAG, $N$-acetyl- $\beta$-D-glucosaminidase; NGAL, neutrophil gelatinase-associated lipocalin; TPF, true-positive fraction.

Table 3. Specificity, sensitivity, positive predictive value, and negative predictive value dependent on urinary $\mathrm{C}$-megalin values

\begin{tabular}{lcccc}
\hline $\begin{array}{l}\text { Cutoff value } \\
\text { of urinary } \\
\begin{array}{l}\text { C-megalin } \\
\text { (pmol/nmol) }\end{array}\end{array}$ & Sensitivity (\%) & Specificity (\%) & $\begin{array}{c}\text { Positive- } \\
\text { predictive } \\
\text { value (\%) }\end{array}$ & $\begin{array}{l}\text { Negative- } \\
\text { predictive } \\
\text { value (\%) }\end{array}$ \\
\hline 4.0 & 78.3 & 85.7 & 90.0 & 70.6 \\
4.5 & 78.3 & 85.7 & 90.0 & 70.6 \\
5.0 & 73.9 & 85.7 & 89.5 & 66.7 \\
5.5 & 73.9 & 85.7 & 89.5 & 66.7 \\
6.0 & 73.9 & 92.9 & 94.4 & 68.4 \\
6.5 & 73.9 & 92.9 & 94.4 & 68.4 \\
7.0 & 65.2 & 92.9 & 93.8 & 61.9 \\
\hline
\end{tabular}

values were calculated as shown in Table 3. Cutoff value of $6.5 \mathrm{pmol} / \mathrm{nmol}$ appeared to have the best diagnostic accuracy yielding a specificity of $73.9 \%$ and a sensitivity of $92.9 \%$. Additionally, there was a significant positive correlation between urinary C-megalin levels and severity of renal scarring $(r=0.55, P=0.0004)$. Renal scarring was mild in nine patients, moderate in six, severe in eight, and no patients had global atrophy.

\section{Multiple Logistic Regression Analysis for the Risk of Renal Scarring Among Confounding Factors}

Multiple logistic regression analysis was performed to assess possible confounding factors other than urinary C-megalin for the risk of developing renal scarring because the grade of VUR was higher in children with renal scarring than those without as shown in Table $1(\mathrm{P}=0.18)$. As a result, only urinary C-megalin levels showed a significant difference $(P=0.007)$ between the renal scarring group and the nonrenal scarring group.

\section{DISCUSSION}

In children, fUTI is a common disease, but its recurrence may lead to renal scarring resulting in $\operatorname{ESRD}(9,12)$. The diagnosis of renal scarring is typically made using ${ }^{99 \mathrm{~m}} \mathrm{Tc}$-DMSA renal scintigraphy. However, only some facilities are able to perform this test, which is invasive and expensive, and thus it is not recommended for all cases of fUTI in children $(4,21)$. Additionally, this test involves exposure to radiation. Therefore, repeatedly performing ${ }^{99 \mathrm{~m}} \mathrm{Tc}$-DMSA renal scintigraphy in children, who are highly sensitive to radiation, is problematic. Consequently, there is a need to identify a biomarker test that can screen the presence of renal scarring in children in a convenient and noninvasive manner.

In this study, we found that, in children with renal scarring as a post-fUTI complication, there was a significant increase in urinary C-megalin levels. Therefore, we demonstrated for the first time that the measurement of urinary C-megalin levels was useful for diagnosing post-fUTI renal scarring. We also showed that the levels of urinary proteins, NAG, and BMG, which have been conventionally and widely used as biomarkers for renal tubular damage and renal scarring, were not useful for diagnosing post-fUTI renal scarring in children. Furthermore, NGAL and L-FABP, which have attracted attention in recent years as biomarkers for kidney damage, were inferior to $\mathrm{C}$-megalin for diagnosing renal scarring. These findings are consistent with recent studies in adults demonstrating that urinary $\mathrm{C}$-megalin levels increase more significantly than BMG and NAG levels from the onset of disease in diabetic nephropathy and IgA nephropathy $(19,22)$. Additionally, the amount of urinary C-megalin excretion was significantly positively correlated with the progression of diabetic nephropathy, histological severity, and the risk of starting dialysis of IgA nephropathy $(19,22)$.

Megalin, a giant protein $(\sim 600 \mathrm{kDa})$ cloned in 1994 (23), is expressed at the apical membrane of proximal tubular epithelial cells (PTECs). Megalin is an endocytosis receptor for the uptake of a variety of ligands that are filtered from the glomeruli into cells (24). Megalin in urine exists as the ectodomain (A-megalin) and full-length (C-megalin) forms, which are measured by amino- and carboxyl-terminal enzyme-linked immunosorbent assay, respectively (19). In our study, with regard to the mechanism of elevated urinary $\mathrm{C}$-megalin levels in renal scarring cases, acute inflammatory cytokines, such as tumor necrosis factor- $\alpha$, were unlikely to be involved because at least 4 months had elapsed since fUTI.

C-megalin excretion is not likely to be increased from scarred nephrons, but could be increased from functional nephrons. We recently showed that urinary C-megalin excretion was increased via exocytosis from residual functioning PTECs that were overloaded with protein metabolism (25). We also speculate that the reason why BMG, NGAL, and L-FABP levels in urine were inferior to megalin for discriminating renal scarring is because these biomarkers are endocytic ligands of megalin (26-28). Therefore, the urinary excretions of BMG, NGAL, and L-FABP were not significant because of the compensatory hyperfunction of megalinmediated endocytosis of these ligands in residual PTECs.

Renal scarring is commonly assessed by radioisotope scintigraphy using ${ }^{99 \mathrm{~m}} \mathrm{Tc}$-DMSA. Until recently, ${ }^{99 \mathrm{~m}} \mathrm{Tc}$ DMSA was assumed to have a high binding affinity to blood 


\section{Articles | Yamanouchi et al.}

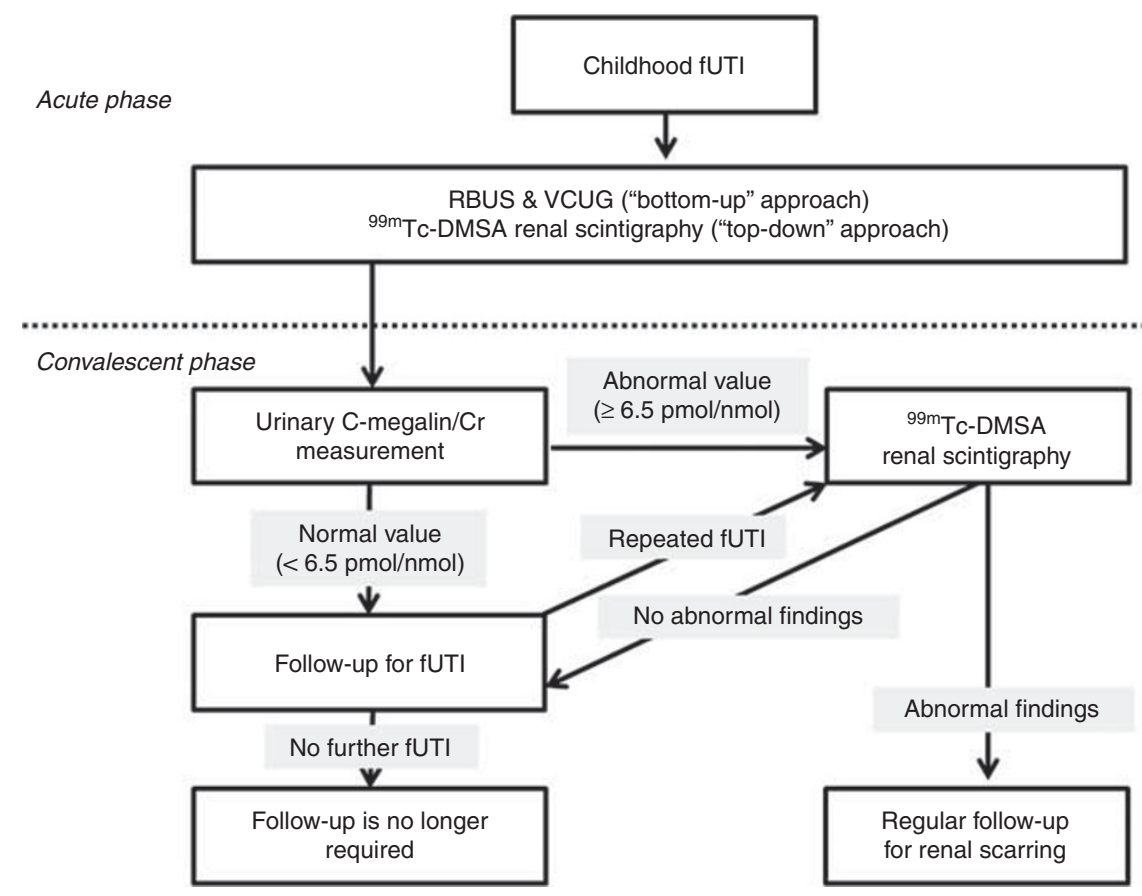

Figure 4. Proposed algorithm of a workup for children with fUTI using urinary C-megalin levels. Regardless of whether a "bottom-up" or "top-down" approach is applied for children with fUTI, urinary C-megalin levels in the convalescent phase (4-6 months after fUTI) should be measured in patients with normal findings of RBUS, VCUG, and DMSA. If children show abnormal C-megalin/ $\mathrm{Cr}$ values ( $\geq 6.5 \mathrm{pmol} / \mathrm{nmol})$, they should be tested with

${ }^{99 \mathrm{~m}}$ Tc-DMSA renal scintigraphy to assess permanent renal scarring. Cr, creatinine; fUTI, febrile urinary tract infection; RBUS, renal-bladder ultrasound;

${ }^{99 m}$ Tc-DMSA, ${ }^{99 m}$ technetium-dimercaptosuccinic acid; VCUG, voiding cystourethrogram.

proteins, and is thus mostly unaffected by glomerular filtration. Approximately $65-90 \%$ of ${ }^{99 \mathrm{~m}} \mathrm{Tc}$-DMSA is present in blood plasma, and thus it might be taken up into PTECs from the basolateral side (29-31). However, an experiment with megalin/cubilin-knockout mice showed that ${ }^{99 \mathrm{~m}} \mathrm{Tc}$ DMSA was bound to $\alpha_{1}$-microglobulin, filtered by glomeruli, and reabsorbed by PTECs via megalin/cubilin (32). In disorders resulting in the decreased expression of megalin in PTECs, such as Dent disease, Lowe syndrome, and Fanconi syndrome, the uptake of ${ }^{99 \mathrm{~m}} \mathrm{Tc}$-DMSA into the kidney is decreased, and it collects in the bladder (33-35). This finding also suggests that ${ }^{99 \mathrm{~m}} \mathrm{Tc}$-DMSA is filtered by glomeruli and taken up by PTECs via megalin and/or cubilin. Therefore, areas of poor accumulation in ${ }^{99 \mathrm{~m}} \mathrm{Tc}$-DMSA renal scintigraphy that have previously been presumed to be sites of renal scarring may in fact be sites of decreased function of megalin and/or cubilin. These areas may also be sites of decreased glomerular filtration of ${ }^{99 \mathrm{~m}} \mathrm{Tc}-\mathrm{DMSA}$ bound to $\alpha_{1}$ microglobulin.

The diagnosis of fUTI in children may facilitate a radiographic workup to identify patients who are susceptible to renal damage. However, a proper diagnostic algorithm has not been established and remains controversial (36). Historically, the examinations used for a workup of children with fUTI most commonly included renal and bladder ultrasound (RBUS) and voiding cystourethrogram (VCUG). Collectively, this is now referred to as the "bottom-up" approach. Patients who are diagnosed with VUR or parenchymal deformity may undergo ${ }^{99 \mathrm{~m}} \mathrm{Tc}$-DMSA renal scintigraphy at a later date
(4-6 months after the episode of fUTI) to assess renal scarring. Alternatively, the "top-down" approach targets the kidney with ${ }^{99 m}$ Tc-DMSA renal scintigraphy to diagnose acute renal parenchymal involvement at the time of fUTI (acute phase). Patients with evidence of parenchymal inflammation are subsequently referred to have VCUG to assess VUR in addition to the following ${ }^{99 \mathrm{~m}} \mathrm{Tc}$-DMSA renal scintigraphy to assess permanent scarring (6). Whichever approach is applied, the possibility of missing patients who develop renal scarring is a concern. In this regard, RBUS is desirable to identify renal scar formation because there is no radiation exposure and it is a noninvasive procedure. However, there are some controversies regarding diagnostic accuracy (37-39), although recent advances in Doppler ultrasonography have improved its sensitivity (40). Patients who have no abnormal findings on RBUS, VCUG, and ${ }^{99 \mathrm{~m}} \mathrm{Tc}-$ DMSA renal scintigraphy in the acute phase should be noted because these patients may not undergo ${ }^{99 \mathrm{~m}} \mathrm{Tc}$-DMSA renal scintigraphy at a later time to assess permanent renal scarring. Therefore, we suggest that urinary C-megalin levels should be measured to detect renal scarring in these patients because the testing method has a specificity of $73.9 \%$, sensitivity of $92.9 \%$, and a cutoff value of $6.5 \mathrm{pmol} / \mathrm{nmol}$ (Table 3, Figure 4).

There were some limitations in the current study. First, only a small number of patients were investigated. Second, the timing of blood sampling varied considerably from 1 to $120 \mathrm{~h}$ because the subjects were diagnosed as having fUTI at diverse medical care facilities. Variations in the time from the onset of fever caused by fUTI to blood sampling might result in 


\section{Urinary C-megalin and renal scarring $\mid$ Articles}

insignificant differences in CRP between the groups as shown in Table 1. Third, we were unable to distinguish patients with congenital renal scarring and dysplastic kidney from those with renal scarring. In such patients, urinary C-megalin levels might have already been elevated before the onset of fUTI. Furthermore, we were unable to conduct ${ }^{99 \mathrm{~m}} \mathrm{Tc}$-DMSA renal scintigraphy in every patient with a history of fUTI. Therefore, there was a possibility of selection bias. Finally, serial urine samples for the measurement of $\mathrm{C}$-megalin were not available. The monitoring of urinary $\mathrm{C}$-megalin levels with time is fundamental to validate its significance in patients with renal scars and should be performed in a future prospective study.

In conclusion, this is the first study to show that measuring urinary C-megalin is useful for diagnosing renal scarring in children who have experienced fUTI. Therefore, measuring urinary C-megalin levels in such children might be useful for the screening of renal scarring. In the future, more patients will need to be evaluated to diagnose post-fUTI renal scarring. This should be performed to discriminate patients with congenital renal scarring, and to identify any correlations among severity of renal scarring, determination of the effectiveness of treatment, and the prognosis of patients.

\section{ACKNOWLEDGMENTS}

We thank Editage (www.editage.jp) and J. Ludovic Croxford, PhD, from Edanz Group (www.edanzediting.com/ac) for English language editing.

\section{STATEMENT OF FINANCIAL SUPPORT}

This study was partly supported by Grants-in-Aid for the Practical Research Project for Renal Diseases, from the Japan Agency for Medical Research and Development. A.S. received research grants from Denka Seiken Co., Ltd.

Disclosure: The authors declare no conflict of interest.

\section{REFERENCES}

1. Chesney RW, Carpenter MA, Moxey-Mims M, et al. Members of the RIVUR Steering Committee, Randomized Intervention for Children with Vesicoureteral Reflux (RIVUR): background commentary of RIVUR investigators. Pediatrics 2008;122:S233-9.

2. Hellström A, Hanson E, Hansson S, et al. Association between urinary symptoms at 7 years old and previous urinary tract infection. Arch Dis Child 1991;66:232-4.

3. Finnell SM, Carroll AE, Downs SM. Subcommittee on Urinary Tract Infection. Technical report-diagnosis and management of an initial UTI in febrile infants and young children. Pediatrics 2011;128:e749-70.

4. Stein R, Dogan HS, Hoebeke P, et al. European Association of Urology; European Society for Pediatric Urology. Urinary tract infections in children: EAU/ESPU guidelines. Eur Urol 2015;67:546-58.

5. Hiraoka M, Hashimoto G, Tsuchida S, et al. Early treatment of urinary infection prevents renal damage on cortical renal scintigraphy. Pediatr Nephrol 2003;18:115-8.

6. Oh MM, Kim JW, Park MG, et al. The impact of therapeutic delay time on acute scintigraphic lesion and ultimate scar formation in children with first febrile UTI. Eur J Pediatr 2012;171:565-70.

7. Matoo TK. Vesioureteral reflux and reflux nephropathy. Adv Chronic Kidney Dis 2011;18:348-54.

8. RIVUR Trial Investigators, Hoberman A, Greenfield SP, et al. Antimicrobial prophylaxis for children with vesicoureteral reflux. N Engl J Med 2014;370:2367-76.
9. Novak TE, Mathews R, Martz K, et al. Progression of chronic kidney disease in children with vesicoureteral reflux: the North American Pediatric Renal Trials Collaborative Studies Database. J Urol 2009;182:1678-81.

10. Bailey RR. Vesico-ureteric reflux and reflux nephropathy. Kidney Int Suppl 1993;42:S80-5.

11. Köhler J, Tencer J, Thysell H, et al. Vesicoureteral reflux diagnosed in adulthood. Incidence of urinary tract infections, hypertension, proteinuria, back pain and renal calculi. Nephrol Dial Transplant 1997;12:2580-7.

12. Silva JM, Santos Diniz JS, Marino VS, et al. Clinical course of 735 children and adolescents with primary vesicoureteral reflux. Pediatr Nephrol 2006;21:981-8.

13. Fidan K, Kandur Y, Buyukkaragoz B, et al. Hypertension in pediatric patients with renal scarring in association with vesicoureteral reflux. Urology 2013;81:173-7.

14. Koçyiğit A, Yüksel S, Bayram R, et al. Efficacy of magnetic resonance urography in detecting renal scars in children with vesicoureteral reflux. Pediatr Nephrol 2014;29:1215-20.

15. Routh JC, Grant FD, Kokorowski PJ, et al. Economic and radiation costs of initial imaging approaches after a child's first febrile urinary tract infection. Clin Pediatr (Phila) 2012;51:23-30.

16. Konda R, Sakai K, Ota $S$, et al. Followup study of renal function in children with reflux nephropathy after resolution of vesicoureteral reflux. J Urol 1997;157:975-9.

17. Mishra J, Dent C, Tarabishi R, et al. Neutrophil gelatinase-associated lipocalin (NGAL) as a biomarker for acute renal injury after cardiac surgery. Lancet 2005;365:1231-8.

18. Portilla D, Dent C, Sugaya T, et al. Liver fatty acid-binding protein as a biomarker of acute kidney injury after cardiac surgery. Kidney Int 2008;73:465-72. .

19. Ogasawara S, Hosojima M, Kaseda R, et al. Significance of urinary fulllength and ectodomain forms of megalin in patients with type 2 diabetes. Diabetes Care 2012;35:1112-8.

20. Rushton HG, Majd M, Chandra R, et al. Evaluation of ${ }^{99 \mathrm{~m}}$ technetiumdimercapto-succinic acid renal scans in experimental acute pyelonephritis in piglets. J Urol 1988;140:1169-74.

21. National Collaborating Centre for Women's and Children's Health (UK). Urinary Tract Infection in Children: Diagnosis, Treatment and LongTerm Management. London, UK: RCOG Press, 2007.

22. Seki T, Asanuma K, Asao R, et al. Significance of urinary full-length megalin in patients with IgA nephropathy. PLoS ONE 2014;9:e114400.

23. Saito A, Pietromonaco S, Loo AK, et al. Complete cloning and sequencing of rat gp330/"megalin," a distinctive member of the low density lipoprotein receptor gene family. Proc Natl Acad Sci USA 1994;91:9725-9.

24. Saito A, Sato H, Iino N, et al. Molecular mechanisms of receptormediated endocytosis in the renal proximal tubular epithelium. J Biomed Biotechnol 2010;2010:403272.

25. De S, Kuwahara S, Hosojima M, et al. Exocytosis-mediated urinary fulllength megalin excretion is linked with the pathogenesis of diabetic nephropathy. Diabetes 2017;66:1391-404.

26. Saito A, Kaseda R, Hosojima M, et al. Proximal tubule cell hypothesis for cardiorenal syndrome in diabetes. Int J Nephrol 2010;2011:957164.

27. Hvidberg V, Jacobsen C, Strong RK, et al. The endocytic receptor megalin binds the iron transporting neutrophil-gelatinase-associated lipocalin with high affinity and mediates its cellular uptake. FEBS Lett 2005;579: $773-7$.

28. Oyama Y, Takeda T, Hama H, et al. Evidence for megalin-mediated proximal tubular uptake of L-FABP, a carrier of potentially nephrotoxic molecules. Lab Invest 2005;85:522-31.

29. deLange MJ, Piers DA, Kosterink JG, et al. Renal handling of technetium99m DMSA: evidence for glomerular filtration and peritubular uptake. J Nucl Med 1989;30:1219-23.

30. Penders J, Delanghe JR. Alpha 1-microglobulin: clinical laboratory aspects and applications. Clin Chim Acta 2004;346:107-18.

31. Freitas RS, Gutfilen B, da Fonseca LM, et al. Evaluation of ${ }^{99 \mathrm{~m}}$ technetiumradiopharmaceutical binding to blood elements using different trichloroacetic acid concentrations. Yale J Biol Med 1996;69:483-8. 


\section{Articles | Yamanouchi et al.}

32. Weyer K, Nielsen R, Petersen SV, et al. Renal uptake of ${ }^{99 \mathrm{~m}} \mathrm{Tc}$ dimercaptosuccinic acid is dependent on normal proximal tubule receptor-mediated endocytosis. J Nucl Med 2013;54:159-65.

33. Lee BH, Lee SH, Choi HJ, et al. Decreased renal uptake of (99m) Tc-DMSA in patients with tubular proteinuria. Pediatr Nephrol 2009;24:2211-6.

34. Kim SE, Cho JT, Lee DS, et al. Poor renal uptake of technetium-99m-DMSA and technetium-99m-MDP in a patient with Fanconi syndrome and near normal glomerular filtration rate. J Korean Med Sci 1994;9:29-34.

35. Timmis A, Jones C, Paize F. An unusual DMSA scan: answer. Pediatr Nephrol 2012;27:225-7.

36. Prasad MM, Cheng EY. Radiographic evaluation of children with febrile urinary tract infection: bottom-up, top-down, or none of the above? Adv Urol 2012;2012:716739.
37. Stember JN, Lynch D, Behr G, et al. Sonographic prediction of pediatric renal scarring with full parameter normalization. J Ultrasound Med 2016;35:1639-43.

38. Hung TW, Tsai JD, Liao PF, et al. Role of renal ultrasonography in predicting vesicoureteral reflux and renal scarring in children hospitalized with a first febrile urinary tract infection. Pediatr Neonatol 2016;57:113-9.

39. Sinha MD, Gibson P, Kane T, et al. Accuracy of ultrasonic detection of renal scarring in different centres using DMSA as the gold standard. Nephrol Dial Transplant 2007;22:2213-6.

40. Mohammadjafari H, Aalaee A, Salehifar E, et al. Doppler ultrasonography as a predictive tool for permanent kidney damage following acute pyelonephritis: comparison with dimercaptosuccinic acid scintigraphy. Iran J Kidney Dis 2011;5:386-91. 